\title{
Feature
}

Meeting Report

\section{Society for the Advancement of Biology Education Research (SABER)}

\author{
Erika G. Offerdahl, ${ }^{* \dagger}$ Teri Balser,,$\$ \S$ Clarissa Dirks, $\neq \| \mid$ Kathryn Miller, \\ Jennifer L. Momsen, ${ }^{\#}$ Lisa Montplaisir, ${ }^{\ddagger \#}$ Marcy Osgood, ${ }^{\ddagger @}$ Karen Sirum,,$\neq * *$

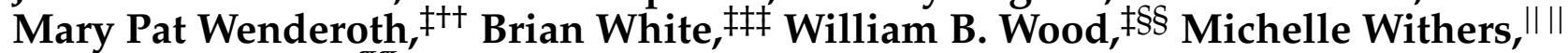 \\ and Robin Wright ${ }^{\mathbb{I I I}}$
}

\begin{abstract}
*Department of Chemistry \& Biochemistry, North Dakota State University, Fargo, ND 58108; §Institute for Cross-College Biology Education, University of Wisconsin-Madison, Madison, WI 53706; "Scientific Inquiry, The Evergreen State College, Olympia, WA 98505; II Department of Biology, Washington University in St. Louis, St. Louis, MO 63130; "Department of Biological Sciences, North Dakota State University, Fargo, ND 58108; ${ }^{\circledR}$ Department of Biochemistry and Molecular Biology, University of New Mexico, Albuquerque, NM 87131; ${ }^{* *}$ Department of Biological Sciences, Bowling Green State University, Bowling Green, OH 43403; ${ }^{+\dagger}$ Department of Biology, University of Washington, Seattle, WA 98195; $¥$ Department of Biology, University of Massachusetts, Boston, Boston, MA 02125; §§Department of Molecular, Cellular, and Developmental Biology, University of Colorado, Boulder, CO 80309; "IIDepartment of Biology, West Virginia University, Morgantown, WV 26505; IIII Department of Genetic, Cell Biology and Development, University of Minnesota, St. Paul, MN 55455
\end{abstract}

\section{INTRODUCTION}

Biology education research (BER) can be a major contributor to the herculean task of modernizing and transforming biology education. However, as researchers in a relatively young and still small field, BER practitioners now find themselves fragmented across 64 biology-related societies and lacking agreement on a core research agenda, a convenient professional network, and venues of dissemination. To begin addressing these needs, the newly formed Society for the Advancement of Biology Education Research (SABER) held an inaugural meeting in September 2010 at the University of Minnesota-Twin Cities. The 29 participants (Figure 1) included faculty, postdoctoral fellows, and graduate students engaged in empirical research and professional development, as well as journal editors, textbook writers, and a textbook editor. The diversity of this group contributed to a thoughtful,

DOI: $10.1087 /$ cbe.10-11-0135

${ }^{\dagger}$ Senior author.

¥These authors contributed equally to the writing.

Address correspondence to: Erika Offerdahl (erika.offerdahl@ ndsu.edu).

(C) 2011 E. Offerdahl et al. CBE-Life Sciences Education (c) 2011 The American Society for Cell Biology. This article is distributed by The American Society for Cell Biology under license from the author(s). It is available to the public under an AttributionNoncommercial-Share Alike 3.0 Unported Creative Commons License (http:/ / creativecommons.org/licenses/by-nc-sa/3.0).

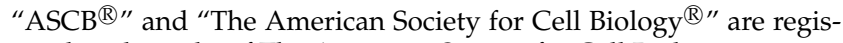
tered trademarks of The American Society for Cell Biology. reflective, and productive meeting, whose major goals were to 1) define BER, 2) identify challenges to its practice, 3) formulate overarching research questions, and 4) outline the role of SABER in supporting the BER community. The consensus views of the participants on each of these goals are described in the paragraphs below.

The outcomes of this meeting are timely in the context of the recently released summary report Vision and Change in Undergraduate Education, A Call to Action, which charged the biology community with "creating, using, assessing, and disseminating effective practices in teaching and learning" (American Association for the Advancement of Science, 2010). By providing the infrastructure needed to create a vibrant network of practitioners, SABER is well positioned to support biology education researchers in generating empirical evidence that can effect meaningful changes in undergraduate biology education.

\section{WHAT IS BER?}

Twenty years ago, in his widely cited work, Scholarship Reconsidered (1990), Ernest Boyer argued that scholarly teaching should receive equal emphasis with disciplinary research at American universities. At about the same time, education researchers in science disciplines began to apply empirical research methods to the assessment of teaching and learning, particularly in physics (e.g., Hestenes et al., 1992). Some practitioners used assessment results to measure and enhance the effectiveness of their teaching (sometimes called action 


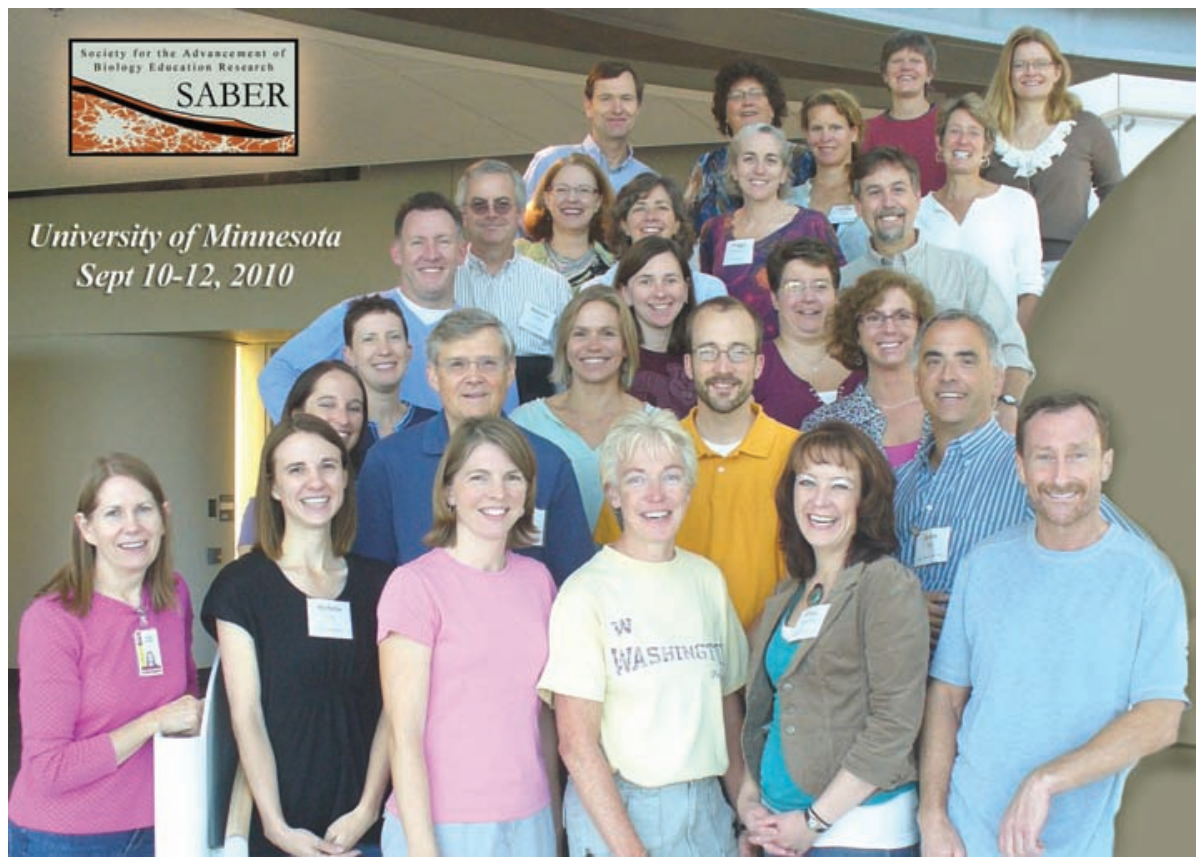

Figure 1. SABER Founding Members: Teri Balser, Clarissa Dirks, Mary Pat Wenderoth, Janet Branchaw, Rob Brooker, Peggy Brickman, Malcolm Campbell, Mark Connelly, Erin Dolan, Scott Freeman, Mark Hens, Jenny Knight, Kathryn Miller, Jennifer Momsen, Lisa Montplaisir, Erika Offerdahl, Marcy Osgood, Nancy Pelaez, Becky Ruden, Jonathon Schramm, Michele Shuster, Karen Sirum, Amber Smith, Michelle Smith, Brian White, Devin Wixon, William Wood, Robin Wright. (Photo Credit: Becky Ruden, founding member) research), and this tradition came to be known as the scholarship of teaching and learning (SoTL). Others used assessment tools to push beyond immediate practical application in their own classrooms and link research on how students learn a specific discipline to results from education and cognitive sciences on how people learn in general (reviewed in National Research Council, 1999), giving rise to the field of discipline-based education research (DBER).

The relation of SoTL to DBER has been the subject of considerable debate (e.g., Kreber, 2002; Boshier, 2009). SABER participants agreed that BER is separate from, though not exclusive of, SoTL or scientific teaching (Handelsman et al., 2007). The group adopted the definition that BER is hypothesis-driven research seeking to create new knowledge about the teaching and learning of biology and to disseminate that knowledge to the broader scientific community.

\section{CHALLENGES TO THE PRACTICE OF BER}

Compared to other areas of DBER, such as chemistry or physics, BER is an adolescent field, and its practitioners face a number of challenges both at the career and day-to-day levels. For example, many of those currently engaged in BER have a PhD in a life sciences discipline but have developed expertise in BER through informal routes and continue to publish biology research in addition to BER. Further, although there are increasing numbers of tenure-track BER faculty members in biology departments, the evaluation criteria for promotion and tenure decisions are often less well defined than for traditional biology faculty. This situation stems, in part, from the fact that the research methods in BER are often distinct from those of other biology colleagues, and there is seldom more than one tenure-track BER faculty member in any given biology department. Moreover, the multiple entry points into the field are not well articulated, and pathways for training and preparing BER scholars have yet to be established. Par- ticipants in the SABER meeting anticipated that these career challenges will lessen as BER matures into an accepted subdiscipline of biology.

Biology education researchers also encounter the daily challenges of keeping abreast of the most current research design and analytical techniques in a field that requires a particularly broad familiarity with the literature in both education and biology. BER is disseminated in a wide range of journals, from discipline-specific venues such as Bioscience and Genetics to educational journals like Journal of Research in Science Teaching. Furthermore, many educational journals in which BER results might be disseminated, such as $C B E-$ Life Sciences Education, have yet to acquire the conventional impact factors that would allow traditional biologists to evaluate the impact of BER work.

Perhaps the greatest challenge in the practice of BER is the isolation in which many BER practitioners work. Unlike Physics Education Research or Chemistry Education Research, BER does not have a unifying society, entity, or venue to enhance collaboration among practitioners and support the growth of BER. Not surprisingly, SABER participants were invigorated by the opportunity to interact with other biology education researchers whom they had not met at other meetings. In fact, this was a primary benefit noted by the SABER founding members in a meeting follow-up survey. When asked about their sense of connection with colleagues in BER as a result of the meeting, all 21 respondents said it had either increased $(16 \%)$ or significantly increased $(84 \%)$.

\section{OVERARCHING RESEARCH QUESTIONS IN BER}

The progressive research agenda envisaged by SABER will focus on the systematic investigation of questions that are unique to teaching and learning biology, while drawing on foundational and ongoing research from the cognitive 
sciences and other areas of DBER. Meeting participants reached consensus on four overarching lines of inquiry:

1. How does learning in biology compare to learning in the other STEM disciplines? What aspects of learning biology are unique to the discipline?

2. How does scientific teaching impact 1) students' long-term conceptual development, 2) ability to think like a scientist, and 3) career path choices in biology?

3. What practices, activities, and assessments promote the acquisition and transfer of those science process skills (or competencies) that make a biologist?

4. What are the most effective pathways for institutionalizing evidence-based teaching?

\section{ROLE OF SABER}

Participants envisioned the new society as supporting a research community dedicated to improving the teaching and learning of biology, particularly at the undergraduate level. One outcome of the meeting was to articulate the role of SABER in the following mission statement:

SABER is a scientific community whose members develop theory and generate evidence with the goal of improving biology education. SABER fosters Biology Education Research (BER) and its dissemination by defining the standards for BER practice, supporting the BER community through training and faculty development programs, and fostering collaborations among BER investigators.

To grow the membership of SABER, the inaugural participants agreed to invite an initial group of about 100 biologists and educators with interests in BER to join the society as charter members. Additional members will be recruited through the SABER website (http://saber -biologyeducationresearch.wikispaces.com), which is now accessible although still under development, as described further below.

One priority of SABER will be to sponsor an annual national meeting that brings together biology education researchers to share their research findings. The first such conference will take place in the summer of 2011 at the University of Minnesota-Twin Cities, from Friday July 29 through Sunday July 31. SABER invites all who are interested in BER, including undergraduate and graduate students, postdoctoral researchers, and administrators, to attend. Chairs and deans will have the opportunity to take part in a preconference administrators' lunch and tour the spectacular new technologyequipped collaborative-learning biology classrooms in the Science Teaching and Student Services building on Friday afternoon of the meeting. The meeting will include plenary sessions, research talks, poster presentations, networking opportunities, and professional development workshops as well as the society's business meeting and a working session of the advisory board.

A call for presentation proposals will be made in January 2011, with abstracts due March 15. Authors of abstracts selected for presentation will be notified in April 2011. Details will be available on the SABER website.
The SABER concept that germinated in Minneapolis this fall must now be transformed into a vibrant and functional society. SABER will provide support and a community of practice for biology education researchers across all disciplines of biology. The society is intended to bring together BER practitioners from other biology societies as well as those from traditional education societies and societies that focus on the SoTL. In coming months, the SABER website will expand to include links to relevant meeting announcements, graduate programs, job postings, and funding opportunities. In addition, SABER plans to offer several members-only services, including access to an expanding and annotated directory of professionals (for students seeking mentors and committee members, and for faculty seeking collaborators or tenure package reviewers), a current annotated bibliography of BER-related literature, and professional development opportunities. SABER will cultivate high research standards, thereby positioning it to collaborate with other professional societies to support faculty and graduate students who are either active in BER or seeking to transition to BER, as well as journals seeking to expand or redefine submission guidelines to include BER-related articles. SABER will periodically survey its members to ensure a dynamic society, in tune with the needs of its membership.

The inaugural meeting of SABER harnessed the energy and enthusiasm of an emerging field and created the inspiration needed to guide its future growth. As the BER community coalesces, we envision SABER not only as an advocate for the BER community but also as a direct response to national calls for the transformation of undergraduate biology education. The meeting participants hope that SABER will provide a framework to unite biology education researchers and shape BER in the 21st century.

\section{ACKNOWLEDGMENTS}

Special thanks to Robin Wright for hosting the event at the University of Minnesota-Twin Cities. This work was funded by NSF Research Coordination Network for Undergraduate Biology Education incubator grant 0955572 .

\section{REFERENCES}

American Association for the Advancement of Science (2010). Vision and Change: A Call to Action (AAAS Report), Washington, DC. http:/ / visionandchange.org (accessed 20 October 2010).

Boshier R (2009). Why is the scholarship of teaching and learning such a hard sell? Higher Educ Res Dev 28, 1-15.

Boyer E (1990). Scholarship Reconsidered: Priorities of the Professoriate, San Francisco: Jossey-Bass.

Handelsman J, Miller S, Pfund C (2007). Scientific Teaching, New York: W.H. Freeman.

Hestenes D, Wells M, Swackhamer G (1992). Force concept inventory. Phys Teach 30, 141-158.

Kreber C (2002). Controversy and consensus on the scholarship of teaching. Stud Higher Educ 27, 151-167.

National Research Council (1999). How People Learn: Brain, Mind, Experience, and School, ed. JD Bransford, A Brown, and RR Cocking, Washington, DC: National Academies Press. 